Special Issue of the 7th International Advances in Applied Physics and Materials Science (APMAS 2017)

\title{
Experimental Study of Flexural Performance of Reinforced Concrete Beams and Hybrid Beams
}

\author{
F. Aydin*, A. SARIBIYik, M. SARIBiyik And M. IPEK \\ Sakarya University of Applied Sciences, Technology Faculty, Civil Engineering Department, 54187 Sakarya, Turkey

\begin{abstract}
This study compared the flexural performance of hybrid beams produced by using concrete in glass fiber reinforced plastic box profiles with concrete beams of the same dimension and concrete properties. Hybrid beams were evaluated in two groups, including standard beams and hybrid beams whose certain properties are improved. Five samples were collected from each test group. Flexure tests were performed on $1500 \times 100 \times 100 \mathrm{~mm}$ hybrid, improved hybrid and reinforced concrete beams, and flexural strength and fracture toughness values were compared. The flexural behavior of hybrid materials, which provide a higher performance increase due to their components than concrete beams, was analyzed. Analyses showed that hybrid materials provided the users with various advantages due to their components; the improved hybrid design had high flexural strength and fracture toughness, while reinforced concrete beams had a higher rigidity than hybrid beams.
\end{abstract}

DOI: 10.12693/APhysPolA.134.244

PACS/topics: GFRP, hybrid, beam, concrete, flexural

\section{Introduction}

Fiber reinforced plastics (FRP), which are one of these new generation composite materials, have gained prominence with their superior mechanical strength, lightness, corrosion resistance and high resistance to chemicals, electrical insulation, low density, and high resistance/density ratio [1-3]. Increased mass production of FRP composites allowed these materials to be more actively used in buildings for various purposes; lightweight and high-resistant fiber reinforced composite materials began to be more widely used for strengthening, repair and renovation purposes in concrete buildings. In recent years, there is increased research on hybrid FRP columns filled with concrete or empty FRP pipes [4]. Scientific research clearly shows that the use of FRP composites in new buildings in the future will mainly focus on hybrid use. Various studies have shown that the combined use of FRP composites with conventional materials like concrete is one of the methods to eliminate some drawbacks and disadvantages of construction elements that are completely made of FRP [5]. They are used in a wide range of fields, including hybrid designs in which FRP composites are used in combination with conventional construction materials, and in the systems that are mainly made of composite profiles.

Similar to various studies which aimed to use the superior properties of concrete and FRP profiles and make these materials positively contribute to each other [6], this study aimed to obtain some advantages from the designed material. Hybrid materials are termed as permanent mold in the literature and do not require a separate mold element [7]. When compared to glass FRP (GFRP)

*corresponding author; e-mail: ferhata@sakarya.edu.tr profiles with two components and plain concrete, elements with smaller cross-sections can be produced with the hybrid materials. Regional and local fractures in GFRP profiles, which have numerous superior properties, under the effect of flexure are eliminated in hybrid design. GFRP box profile does not allow external water or moisture into the concrete; it also makes the procedure which is vital for concrete-curing very advantageous by preventing the concrete filling the box profile in plastic thickness to lose its water or moisture. Furthermore, although resistance and rigidity increase is expected in this hybrid material due to its components, a more impermeable and insulated material will be produced [8].

\section{Experimental procedure}

Serial test samples were produced to compare flexural behavior of GFRP-concrete hybrid beams and reinforced concrete beams. Five samples were collected from concrete, hybrid, and improved hybrid beams, making a total of $15100 \times 100 \times 1500 \mathrm{~mm}$ beams. Four-point flexure tests were applied on the samples. Liquid fresh concrete used in concrete and hybrid beams was prepared. Beams were prepared by pouring some of the fresh concrete in GFRP box profiles and pouring the remaining concrete in previously prepared reinforcement beam molds. Vertical reinforcements with a diameter of $10 \mathrm{~mm}$ and stirrups with a diameter of $8 \mathrm{~mm}$ were prepared to make reinforced concrete beams. Stirrup spacing was $250 \mathrm{~mm}$ and total beam length was $1500 \mathrm{~mm}$. The molds prepared for reinforced concrete beams, placing beam reinforcements inside, and the final version of the samples are presented in Fig. 1. Reinforced concrete beams were cured after being removed from molds. The beams were tested in a test setup using data logger, load cell, and potentiometer 28 days after removal from the molds. Beam samples with a cross-section of $100 \mathrm{~mm}$ and length of $1500 \mathrm{~mm}$ were subjected to four-point flexural tests with $1350 \mathrm{~mm}$ effective span. 

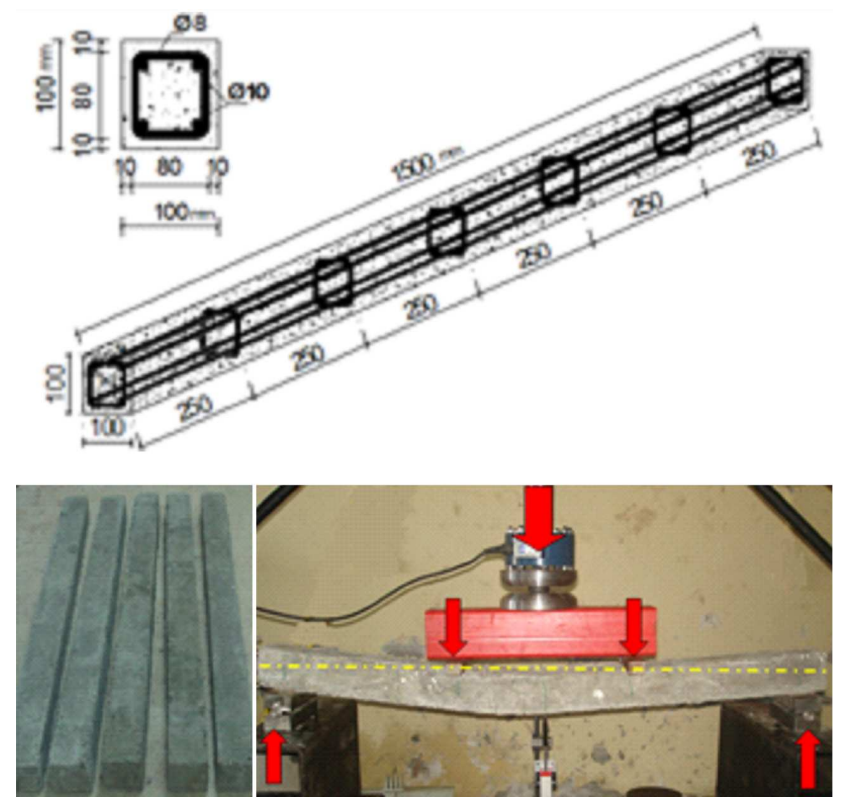

Fig. 1. Details of reinforced concrete beams and flexural test.

The physical and mechanical properties of GFRP box profiles which were used to produce hybrid and improved hybrid beams were experimentally determined. Firstly, the resin burning method was used to experimentally determine the fiber ratios of GFRP box profiles. The fiber ratios of standard GFRPs by volume were found to be $27 \%$ and $13 \%$. The vertical fiber ratio of the samples with additional felt was found to be $22 \%$ and the felt fiber ratio was found to be $14 \%$ by volume. The felt amount of additional felt profiles are increased by $50 \%$ (according to total amount of fibers in profile). Unit weight, specific gravity, Poisson's ratio, modulus of elasticity and tensile strength of GFRP profiles were determined by experimental studies. The physical and mechanical properties of GFRPs in experiments which used a high number of samples are presented in Table I.

TABLE I

Properties of GFRP

\begin{tabular}{l|c}
\hline \hline Young modulus $\left(E_{x}\right)$ & $29300 \mathrm{~N} / \mathrm{mm}^{2}$ \\
tensile strength $($ axial $)$ & $550 \mathrm{~N} / \mathrm{mm}^{2}$ \\
Young modulus $\left(E_{y}\right)$ & $6840 \mathrm{~N} / \mathrm{mm}^{2}$ \\
tensile strength (lateral) & $7.80 \mathrm{~N} / \mathrm{mm}^{2}$ \\
Poisson ratio & 0.34 \\
specific gravity & 1.82
\end{tabular}

Two types of hybrid beams were manufactured: standard and improved hybrid samples. Standard hybrid beams were produced by filling GFRP profiles with fresh concrete. In improved hybrid beams, felt fiber amount was increased by $50 \%$, and profiles that are vertical to the axis with improved resistance and increased concrete adherence by adhering sand with a diameter of $1-3 \mathrm{~mm}$ to the inner surface of the profile were used. Hybrid beams of the same size of the reinforced concrete beams were produced by filing GFRP box profiles with liquid concrete. Flexural tests were conducted on 5 beams from each test group (Fig. 2).

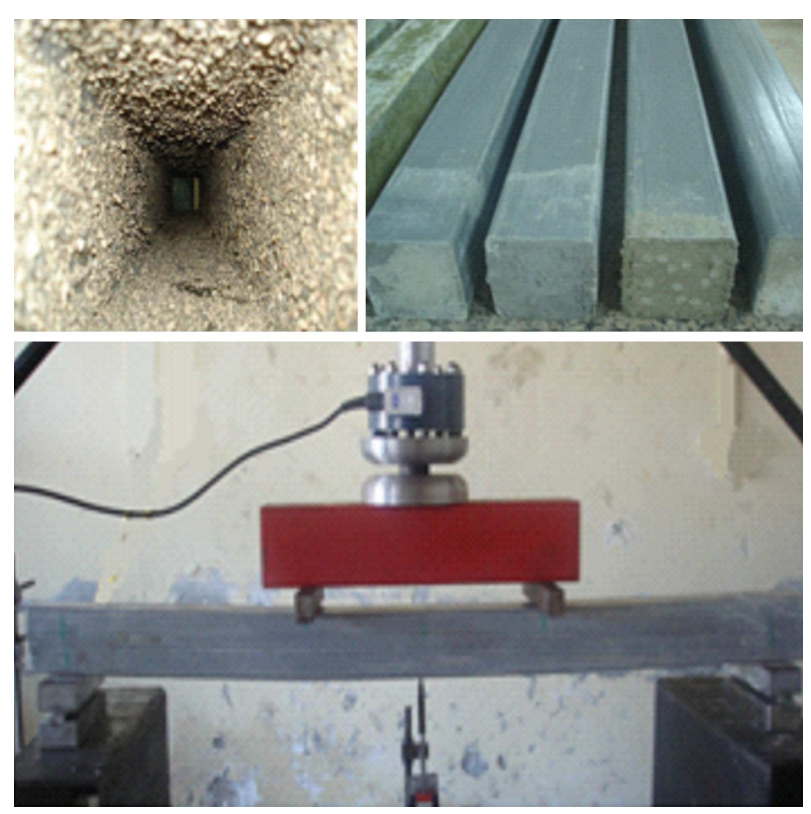

Fig. 2. Hybrid beams and flexure test.

\section{Experimental results and discussions}

Mean flexural load of reinforced concrete beams was calculated as $21190 \mathrm{~N}$, flexural strength was calculated as $28.61 \mathrm{~N} / \mathrm{mm}^{2}$ and fracture toughness was calculated as $341088 \mathrm{~N} \mathrm{~mm}$. Load-deflection graphs of reinforced concrete beams are presented in Fig. 3. It is understood from the flexural strength graphs of concrete samples that all samples showed a linear behavior until $20000 \mathrm{~N}$, after the first crack and yielding occurred in steel reinforcements. Flexural tests on standard hybrid beam samples showed that mean flexural load was $16220 \mathrm{~N}$, flexural behavior was $21.90 \mathrm{~N} / \mathrm{mm}^{2}$ and fracture toughness was $196328 \mathrm{~N} \mathrm{~mm}$. It was found that the flexural load, flexural strength and fracture toughness values of improved hybrid beams were $35384 \mathrm{~N}, 47.99 \mathrm{~N} / \mathrm{mm}^{2}$ and $815142 \mathrm{~N} \mathrm{~mm}$, respectively. Example graphs of hybrid and improved hybrid beams are presented in Figs. 3 and 4. According to flexure graphs of hybrid beams, in all samples, fractures began in the concrete inside the profiles under $5000 \mathrm{~N}$ load; it showed a linear behavior until $15000 \mathrm{~N}$ with increased load and the first fracture occurred under approximately $5000 \mathrm{~N}$. It was observed that improved hybrid beams showed a linear behavior until $35000 \mathrm{~N}$ when sudden fractures occurred. It was found that flexural strength, fracture toughness, and rigidity increased when compared to hybrid beams. After the tests, all graphs representing each sample group were shown and compared in a single graph (Fig. 4). 

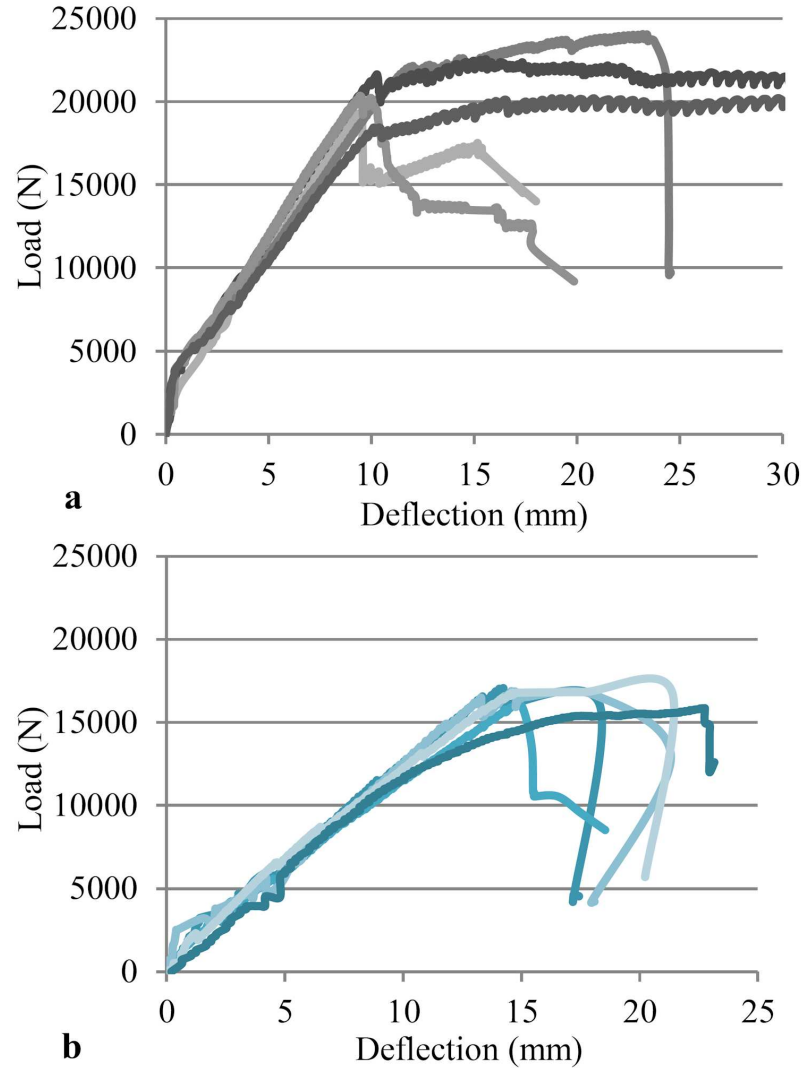

Fig. 3. (a) Reinforced concrete beams flexural graphs, (b) hybrid beams flexural graphs.

Flexural performance of hybrid beams and improved hybrid beams were compared with those of classical reinforced concrete beams. It was found that concrete beam rigidity was $55 \%$ higher than those of improved hybrid beams and no sudden ruptures occurred. It was found that the rigidity of improved hybrid beams produced by increasing concrete adherence and the lateral felt amount of the hybrid beam with low flexural strength increased by $5 \%$ when compared to normal hybrid beams due to increased flexural strength and energy absorption capacity (Fig. 5).

It was found that the flexural strength of improved hybrid samples increased by $67 \%$ when compared to those of reinforced concrete beams with the same dimensions and by approximately 2 times when compared to standard hybrid samples. Fracture toughness values of different sample types are calculated and compared in Fig. 5. Fracture toughness of improved hybrid sample is 2.4 times higher than that of reinforced concrete beams with the same dimensions, and 4 times higher than that of standard hybrid samples. Hybrid material provided significant increases both in compressive strength and flexural strength.

Compressive strength of hybrid material increased from $30 \mathrm{MPa}$ to $46 \mathrm{MPa}$ and flexural strength increased from approximately $29 \mathrm{MPa}$ to $48 \mathrm{MPa}$. Furthermore, the degree of advantage hybrid beams will be
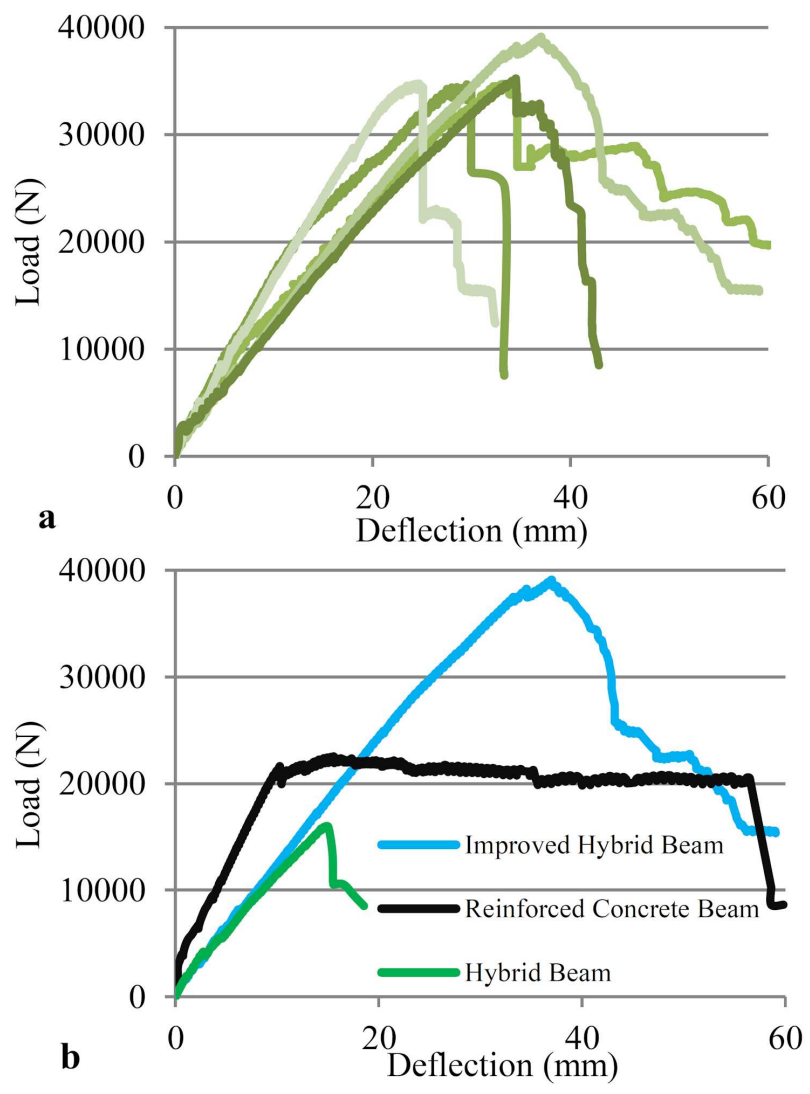

Fig. 4. (a) Improved hybrid flexural graphs, (b) comparison of the beam graphics.
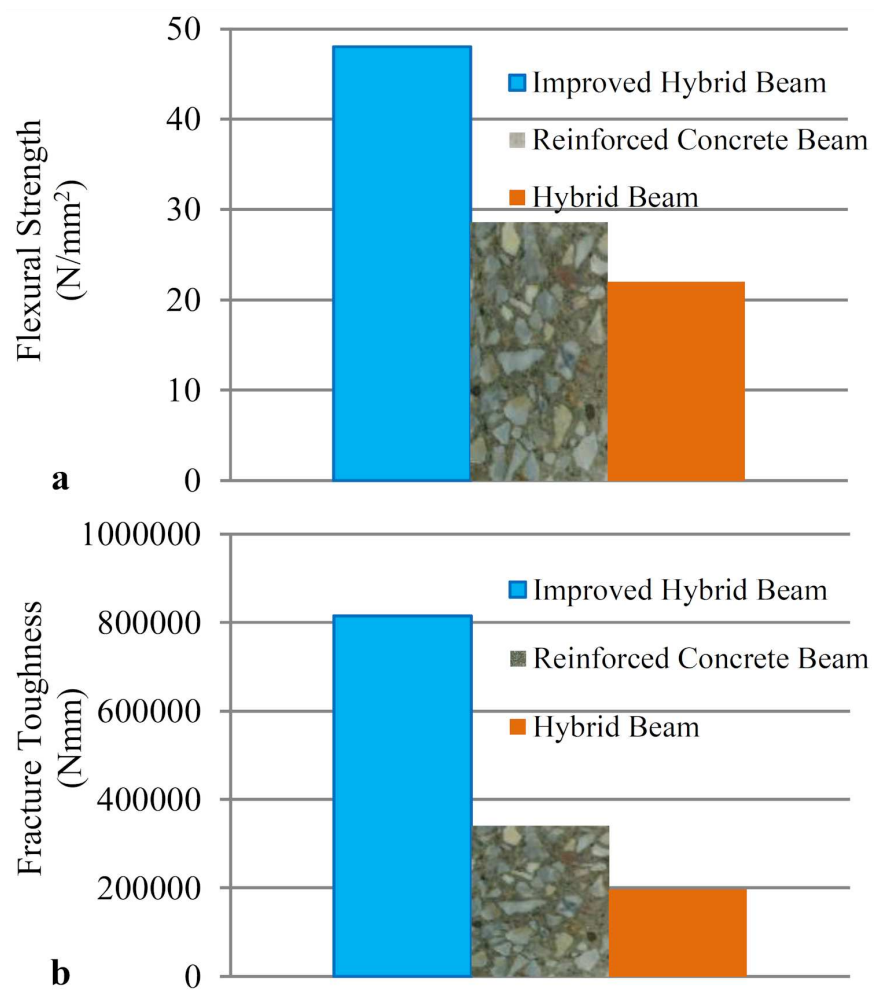

Fig. 5. (a) Comparison of flexural strength, (b) comparison of fracture toughness. 
provided due to lightness was calculated. It was found that hybrid beams were $12.7 \%$ lighter than reinforced concrete beams.

\section{Conclusion}

It was found that improved hybrid beams produced by increasing felt amount by $50 \%$ and adhering sand to the inner surface of the profiles had higher flexural strength than normal hybrid beams and reinforced concrete beams of the same dimensions. Concrete beam rigidity was $55 \%$ higher than that of hybrid beams. It was found that rigidity increased by $5 \%$ compared to normal hybrid beams due to increased flexural strength and energy absorption capacity due to improvement of hybrid beams. Flexural strength and fracture toughness of reinforced concrete beams were found to be $28.6 \mathrm{~N} / \mathrm{mm}^{2}$ and $341088 \mathrm{~N} \mathrm{~mm}$, respectively. Flexural strength and fracture toughness of hybrid beams were found to be $21.90 \mathrm{~N} / \mathrm{mm}^{2}$ and $196328 \mathrm{~N} \mathrm{~mm}$, respectively. Flexural strength and fracture toughness of improved hybrid beams were found to be $47.77 \mathrm{~N} / \mathrm{mm}^{2}$ and $815142 \mathrm{~N} \mathrm{~mm}$, respectively. It was found that the flexural strength of improved hybrid beams increased by $67 \%$ when compared to reinforced concrete beams with the same dimensions and by approximately 2 times when compared to standard hybrid samples. Fracture toughness of improved hybrid samples increased by 2.4 times when compared to reinforced concrete beams with the same dimensions and by 4 times when compared to standard hybrid samples. The compressive strength of hybrid materials made of concrete and GFRP increased by $36 \%$ when compared to the concrete of the same dimensions, while flexural strength increased by $60 \%$ when compared to concrete. In addition to increased strength, it was found that hybrid beams were approximately $13 \%$ lighter than reinforced concrete beams.

\section{References}

[1] J.P. Won, Y.N. Yoon, B.T. Hong, T.J. Choi, S.J. Lee, Compos. Struct. 94, 1236 (2012).

[2] H. Jun, L. Yuqing, C. Airong, D. Liang, Constr. Build. Mater. 26, 49 (2012).

[3] J.A. Gonilha, J.R. Correia, F.A. Branco, Compos. Struct. 95, 453 (2013).

[4] H.J. Joo, S.S. Lee, S.J. Yoon, J.K. Park, K.Y. Shin, Adv. Mater. Res. 26-28, 329 (2007).

[5] E. Schaumann, Ph.D. Thesis, École Polytechnique Fédérale De Lausanne, Switzerland 2008.

[6] B. Gautam, T. Matsumoto, Compos. Struct. 89, 20 (2009).

[7] L. Tianhong, F. Peng, Y. Lieping, in: Third International Conference on FRP Composites in Civil Engineering (CICE 2006), Miami (FL), 2006.

[8] F. Aydın, M. Sarıbıyık, Constr. Build. Mater. 41, 563 (2013). 